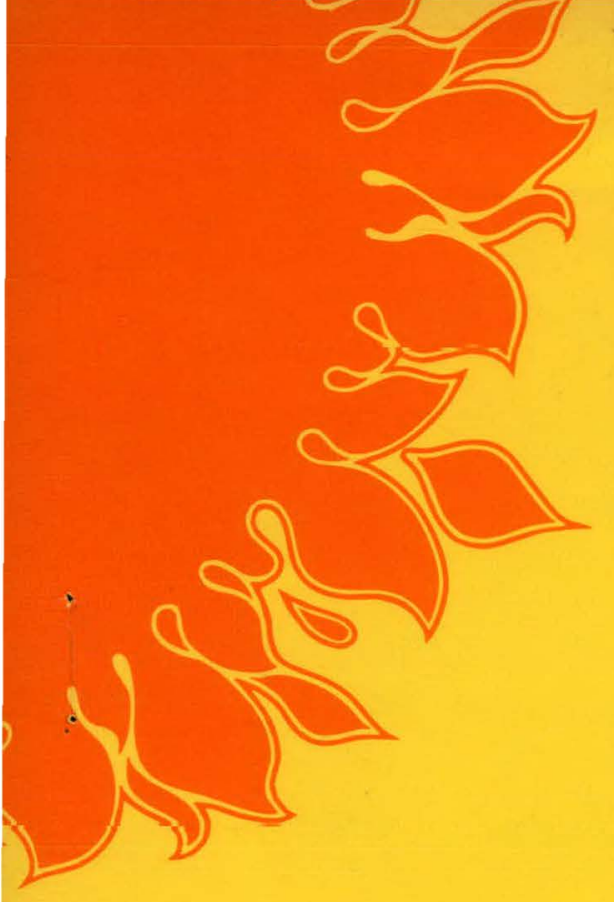

\title{
$D R-277$
}

\section{MASTER}

\section{WEB-DENDRITIC RIBBON GROWTH}

USC Solar Report No. Q-3

Quarterly Report, April 1, 1976-June 30, 1976

R. B. Hilborn, Jr.

J. W. Faust, Jr.

June 22, 1976

Work Performed Under JPL Contract No. 954344

College of Engineering

South Carolina University

Columbia, South Carolina

\section{ENERGY RESEARCH AND DEVELOPMENT ADMINISTRATION}

\section{Division of Solar Energy}




\section{DISCLAIMER}

This report was prepared as an account of work sponsored by an agency of the United States Government. Neither the United States Government nor any agency Thereof, nor any of their employees, makes any warranty, express or implied, or assumes any legal liability or responsibility for the accuracy, completeness, or usefulness of any information, apparatus, product, or process disclosed, or represents that its use would not infringe privately owned rights. Reference herein to any specific commercial product, process, or service by trade name, trademark, manufacturer, or otherwise does not necessarily constitute or imply its endorsement, recommendation, or favoring by the United States Government or any agency thereof. The views and opinions of authors expressed herein do not necessarily state or reflect those of the United States Government or any agency thereof. 


\section{DISCLAIMER}

Portions of this document may be illegible in electronic image products. Images are produced from the best available original document. 


\section{NOTICE}

This report was prepared as an account of work sponsored by the United States Government. Neither the United States nor the United States Energy Research and Development Administration, nor any of their employees, nor any of their contractors, subcuntracturs, ur thein enpluyees, makes any wantanly, expess un inplied, ur assunes any legal liability or responsibility for the accuracy, completeness or usefulness of any information, apparatus, product or process disclosed, or represents that its use would not infringe privately owned rights.

This report has been reproduced directly from the best available copy.

Available from the National Technical Information Service, U. S. Department of Commerce, Springfield, Virginia 22161

Price: Paper Copy $\$ 4.00$ (domestic)

$\$ 6.50$ (foreign)

Microfiche $\$ 2.25$ (domestic)

$\$ 3.75$ (foreign) 
Web-Dendritic Ribbon Growth

USC Solür Report No. Q-3

Quarterly Report for Period 4-1-76 to $6-30-76$

Authors: R. B. Hilborn, Jr. and J. W. Faust, Jr.

Date of Publication: $6-22-76$.

JPL Contract No. 954344

Contractor: University of South Carolina

College of Engineering

Columbia, S.C. 29208

- This work was performed for the Jet Propulsion Laboratory, California Institute of Technology, under NASA Contract NAS7-100 for the U.S. Energy Research and Development Administration, Division of Solar Energy.

The JPL Low-cost Silicon Solar Array Project is funded by. ERDA and Forms part of the ERDA Photovoltaic Conversion Program to initiate a major effort toward the development of low-cost solar arrays. 


\section{TABLE OF CONTENTS}

SUBJECT

Technical Content Statement

Abstract

Man-hours and Cost Totals

Summáry of Results

Review by Task Element.

Interpretation of Results

Tentative Conclusions

Projection of 'Next Quarter's Activity

Summary of Characterization Data

Program Plan
PAGE

1

1

1

$1-2$

3

19

19

20

20

Attachment 
Technical Content Statement

This report contains information prepared by the University of South Carolina under JPL subcontract. Its content is not necessarily endorsed by the Jet Propulsion Laboratory, California Institute of Technology, National Aeronautics and Space Administration, or the U.S. Energy Research and Development Administration, Division of Solar Energy.

Abstract

This is a report of the third quarter's work on the web-dendritic ribbon growth at the University of South Carolina. A brief description of the work initiated and carried out during this period to meet the program goals is given along with a copy of the Program Plan covering the entire period of. the contract.

Man-Hours and Cost Totals

\begin{tabular}{|c|c|c|c|c|c|}
\hline \multicolumn{2}{|c|}{ Previous } & \multicolumn{2}{|c|}{ Current Quarter } & \multicolumn{2}{|c|}{ Cumulative } \\
\hline Man-hours & $\cos t$ & Man-hours & $\cos t$ & Man-hours & $\cos t$ \\
\hline 5137 & $\$ 65,876$ & 3123 & $\$ 49,885$ & 8260 & $\$ 115,761$ \\
\hline
\end{tabular}

The web growth investigation portion of this program.was spent in growing a backlog of primitive dendrites and developing a number of dendritic seed crystals having a variety of twin plane spacings. These seeds are to be used in the determination of the optimum twin spacing for dendritic-web growth. Having determined the optimum twin spacing for the seed dendrites, the optimized seeds will be used in the experimental part of the investigation to determine the limitation on the growth width and pull rate of the dendritic- 
web section.

Primitive dendrites containing 2,3,4 and 5 twin planes with twin plane spacings of 0.6 to $19.2 \mathrm{~mm}$. have been grown. A supply of dendrite - seed crystals have been grown from these primitive dendrites.

Computer programs have been developed that appear adequate for the thermal analysis of the dendritic-web growth. A preliminary two dimensional thermal model of the melt, crucible, susceptor and lid has been completed and numerical results obtained. In this model only radiation heat transfer was assumed for the iid. The temperature profiles obtained were thus lower than is found experimentally in the furnace. The model is currently being revised to include conduction and convection losses to the argon gas ambient.

The characterization experiments have all been tested and found adequate for characterization of the material grown in the dendritic-web furnace. 
Review by Task Element

T.E. 1.2.1: Pull nominal web based on 1965 experience; establish measurements baseline

In the last quarterly report $(Q-2)$, progress in controlling the center of therinal symmetry, broadening the lateral temperature gradient, and improving the vertical temperature gradient in the melt was sumnarized. The stability of the melt was evidenced by the fact that we have pulled dendrites thirty feet long before being purposely terminated. Webs have been grown up to 2 feet before termination. Dendrite pulls are longer because we are growing materials for seeds. Webs are only grown long enough to get the necessary observations. and/or data.

Sandblasting of the crucible was studied further and appears to have eliminated the occasional problem of the melt staying off center. Sandblasting is now a part of the crucible preparation procedures.

The installation of the $x-y$ motion on the r.f. coil, mentioned in the last report, to go with the already existing $z$ motion was completed and contributed to the control of the center of thermal symmetry.

It was also pointed out again that the twin spacing for silicon dendrite or web growth had never been optimized. Values of the twin spacing that we were using were given, and the suggestion was made that the spacing was too narrow. It was deemed in the best interests of the contract to spend as much of this report period as necessary in growing primitive dendrites, and from these, pulling long dendrites to be used for seeds for web growth. The other part of the report period was used to gain information on parameters. involved in the three equations used in the thermal modeling discussed in T.E. 1.3. Primitive dendrites were grown by quickly dipping a seed of silicon 
into the supercooled melt. Silicon grows rapidly on this "cold" seed, and must be pulled quickly from the melt. The resulting growth mass contains many "growth mistakes" in the form of twins. Only those twin spacings that sustain growth by the twin plane reentrant edge mechanism will result in primitive dendrites protruding from the growth mass. The growth mass with the few protruding primitive dendrites was usually too large to be pulled through the largest opening in our heat shield. A new heat shield for primitive dendritic growth was made as shown in Fig. 1 .

The primitive dendrites were fractured from the growth mass and the twin spacing measured. A start has been made on pulling longer dendrites for seeds as web growth and in studying their behavior to find the optimum spacing.

The web-growth facility was out of operation for three weeks during this report period due to the necessity of fabricating and installing a closed distilled water cooling system for the $r . f$. generator.

T.E. 1.2.2: Vary pull rate; measure effects, etc.

Our initial range of pull rates covered pull rates of dendrites quite well but was at the top of the range desired at present for pulling webs. A smaller drive wheel was installed. The change to the smaller drive gave not only an improvement in the webs but also a better control over the button formation. Both webs and dendrites have been taken to pull-out by increasing the pull rate. No actual data on the effect of pull rate on dendrites or webs is given because the thermal conditions changed from pull to pu11. 


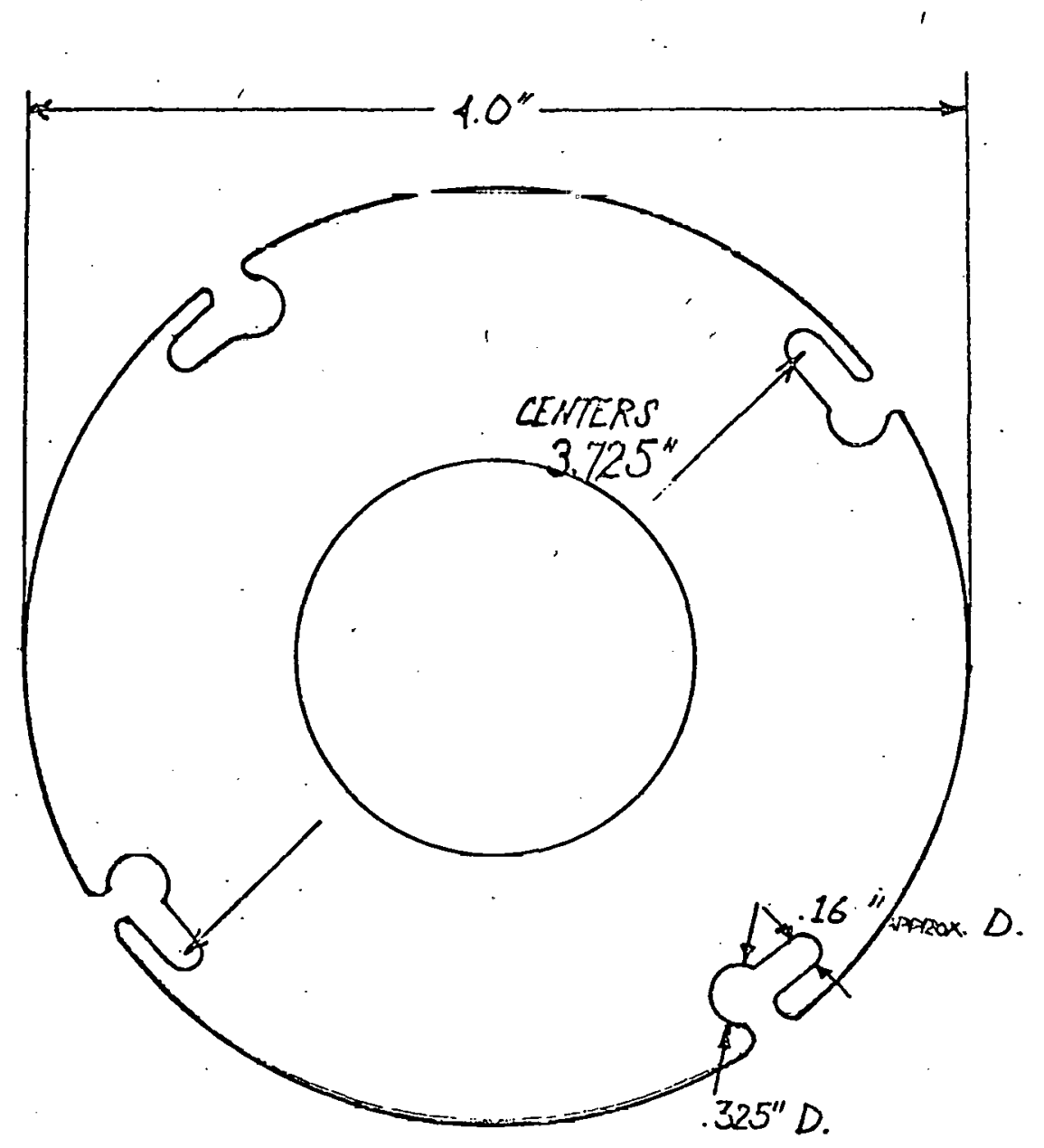

- FIGURE 1. Heat Shield for Pulling Primitive Dendrites 
T.E. 1.2.3: Vary r.f. heat transfer rate, etc.

As mentioned in 1.2.1, the center of thermal symmetry and the thermal conditions in the melt are such that the growth of two-dendrite webs can be sustained. The parameters now under study or that have been varied are:

(a) $T$, temperature of the melt; (b) $V$, velocity of pull; (c) $d T / d z$, temperature gradient into the melt; and (d) $H$, total irradiation. These are found, either directly or implicitiy, in equations $1 ; 2$, and 3 given in the discussion under section T.E. 1.3.

The temperature of the melt, $T$, and the pull velocity, $V$, were taken up in previous reports, and the pull rate is discussed in 1.2.2. The temperature of the melt can be changed by adjustment of the $r . f$. input over a moderate range or by adjusting the height of the susceptor in the r.f. coil. The latter method, which must often be used, also changes the very important temperature gradient, $\mathrm{dT} / \mathrm{dz}$,

Our preliminary experiments for determining the contribution of other effects on $d T / d z$ consisted of:

(a) Shape of susceptor. A susceptor was made that has the same diameter at the bottom as at the top, rather than tapered. This increase in diameter at the bottom decreased the $\mathrm{dT} / \mathrm{dz}$.

(b) The heat loss by conduction into the pedestal was reduced by putting an alumina spacer between the susceptor and the pedestal. This gave an even more dramatic decrease in $\mathrm{dT} / \mathrm{dz}$.

(c) A new heat shield was made from vacuum-deposited Mo which has a very shiny surface and thus a high reflectivity. The higher reflectivity increased $\mathrm{H}$ causing the temperature of the melt, $T$, to be increased and thus decreased $d T / d z$. Seeding was not possible with this shield even when the $T$ was decreased by lowering the susceptor. Sandblasting was required to bring 
back its old value.

(d) $\mathrm{H}$ and also $\mathrm{T}$ (and thus $\mathrm{dT} / \mathrm{dz}$ ) were varied by changing the opening in the heat shield as reported earlier. After heaters were placed on the heat shield to reduce the radiation losses from the web as shown in Fig.2. It also cuts down some on the radiation loss from the melt.

(e) A new dunbell shaped heat shield was made. The drawing for it is given in Figure 3 . This was aimed at changing the radiation loss from the melt and in improving the $d T / d z$ at the center of the melt. 

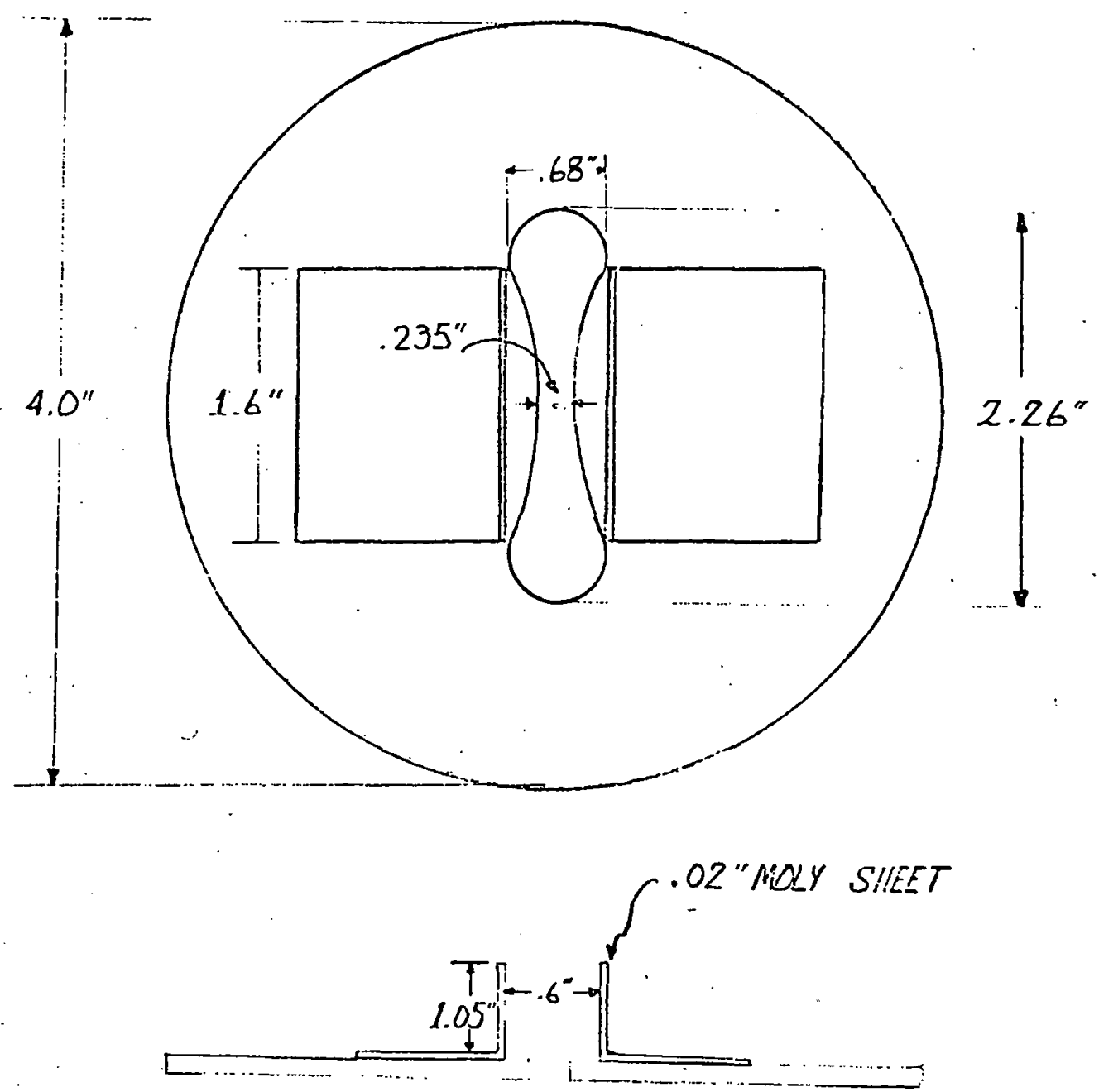

NOT TO SCALE

FIGURE 2. Afterheaters 


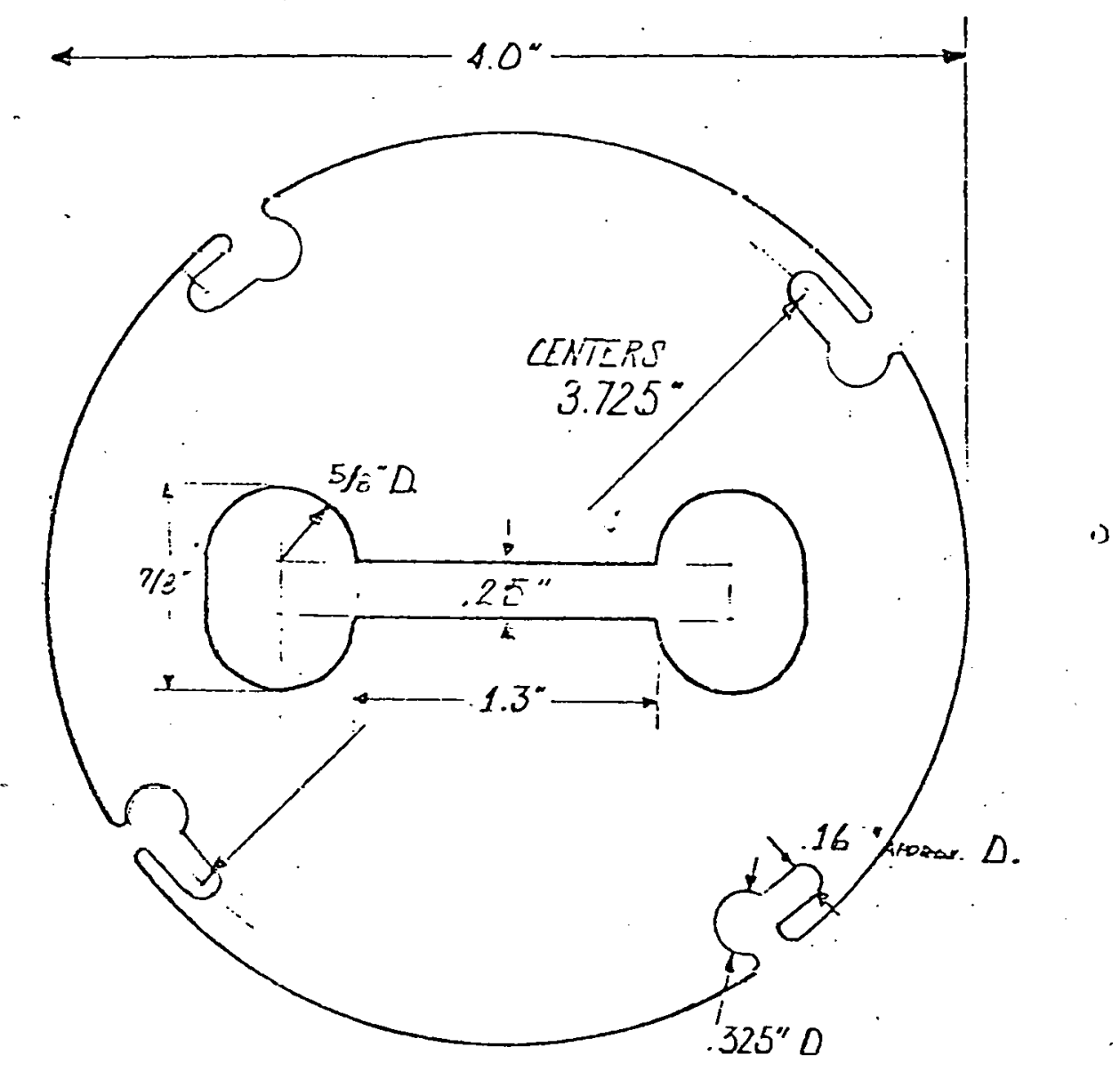

Figure 3 
T. E. 1.3: Web-Growth Analys is

a: Web Thermal Anaiysis

The temperature distribution in the web and meniscus is being investigated with a one-dimensional heat transfer model. Figure 4 shows a cross-section of the web and meniscus. Temperature variations in the zdiractions are expected to be large compared to variations across the width and thickness. Heat transfer occurs in the z-direction by thermal conduction and heat convection as a result of pulling the web. Heat exchange between the surface and surroundings is by, thermal convection and radiation.

The differential equations for the temperature variation with elevation can be determined by an energy balance on a small elemental volume. The differential equations for the temperature variation in the web and meniscus are respectiveity,

$$
\frac{d^{2} T}{d z^{2}}+\frac{\rho_{s} C_{p s} V}{K_{s}} \frac{d T}{d z}-\frac{h P}{K_{s} A_{s}}\left(T-T_{d}\right)-\frac{(W-\alpha H)}{K_{s} A_{s}}=0
$$

and

$$
\begin{aligned}
& \frac{d^{2} T}{d z^{2}}+\frac{1}{A_{m}} \frac{d A_{m}}{d z}+\frac{\rho_{s} C_{p m} A_{s} V}{K_{m} A_{m}} \frac{d T}{d z}-\frac{h P}{K_{m} A_{m}}\left(T-T_{d}\right) \\
& -\frac{(W-\alpha H)}{K_{m} A_{M}}=0
\end{aligned}
$$

where

$$
\begin{aligned}
& A-\text { cross-sectional area } \\
& c_{p}-\text { specific heat } \\
& H-\text { total irradiance of surface } \\
& h-\text { convertive heat transfer coefficient } \\
& K \text { - thermal conductivity } \\
& P \text { - perimeter }
\end{aligned}
$$




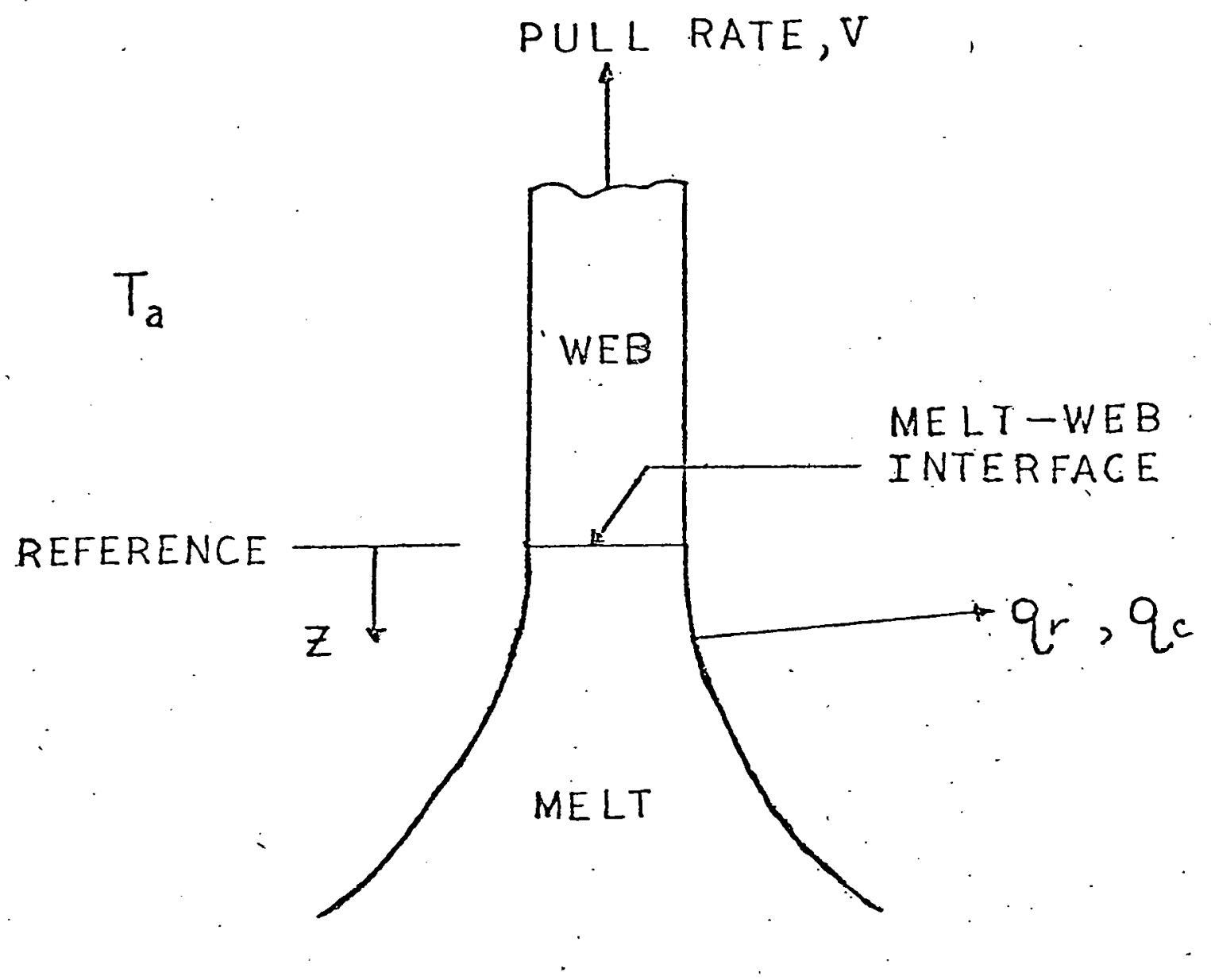

Figure 4. Cross-Section of Web and Meniscus at the Liquid-Sol id Interface 
T. - temperature of web or meniscus

$T_{a}$ - temperature of atmosphere

$\checkmark$ - web pull velocity

W - emissive power of surface

$z$ - distance from liquid -solid interface

$\alpha$ - thermal radiation absorptance of surface

$\rho$ - density

Subscripts $s$ and $m$ indicate solid and melt, respectively.

A thermal balance at the liquid-solid interface yields the following interface condition,

$$
-\left.K_{s} A_{s} \frac{d T}{d z}\right|_{s}+\left.K_{m} A_{m} \frac{d T}{d z}\right|_{m}+\rho_{s} A_{s} V L=0
$$

where $L$ is the latent heat of fusion of the silicon and $\left.\frac{d T}{d z}\right|_{S}$ and $\left.\frac{d T}{d z}\right|_{m}$ are respectively the temperature gradients in the web and melt at the interface. It is assumed in Equation (3) that the temperature of the solid and liquid are equal at the interface, that is, interface subcooling is negligible.

Because of the complexity of the governing differential equations given by Equation (1) through (3) an analytical solution is not possible: Therefore, numerical solutions will be obtained using the computer. The CSMP3 computer program is currently being investigated as a means for obtaining numerical solutions. Preliminary results have been encouraging and it is expected that numerical data $: i l l$ be forthcoming.

The greatest difficulty in obtaining accurate temperature calculations is predicting the irradiance, $H$, of the web and meniscus. The term is contained in Equation ( 1 ) and ( 3 ) and is the thermal radiation received primarily from the lid and silicon melt. The value of $H$ is a function of $z$ since the view factor from the lid and silicon melt varies with position. Initial calculations will be performed with very approximate estimates of $H$ but we will continue to study this problem in order to improve the calculations. 
Thermal Model of the Melt, Crucible, Susceptor, and Lid

Figure 5 shows the nodal geometry for the thermal model presently being used to represent heat transfer in the melt, crucible, susceptor, and lid. Due to the cylindrical geometry of the system, the length of the nodes increases with radial distance from the central axis.

As a result of the thermal effect of the slot in the lid and the web, an azimuthal temperature variation in temperature exists which causes a three-dimensional temperature variation. The three dimensional nodal geometry is obtained by sectioning at increments of azimuthal angle: Howfver, it is seen in Figure 6 that the symetry exists about diametrical lines: ong the slot and perpendicular to the slot. Consequently, thermal modeli f of the $90^{\circ}$ section is sufficient to determine the temperature field. ne $90^{\circ}$ section will be incremented into four "pie" sections of $22.5^{\circ} \mathrm{ir}$.rements. Induction heating by the RF field is present prim. ily in the outer periphery of the susceptor. The nodes in thi: " : on have a thickness equal to the skin depth of approximately $0.059 \mathrm{~cm}$ and are sc.3n in Figure 5 . Heat generation also occurs in the outer periphery of the lid and is also included in the model. Internal heat generation is assumed uniform $u_{p}$ to the skin depth and zero elsewhere.

Heat transfer through the quartz crucible is due to solid conduction and thermal radiation transmitted through the quartz. The quartz is transparent to a large fraction of the radiant energy emitted by the silicon and molybden um surfaces..

The lid is heated by radiation heat transfer from the silicon melt and the crucible. The lid in turn radiates heat to the surroundings from the upper surface. Conduction and convection heat transfer to the 

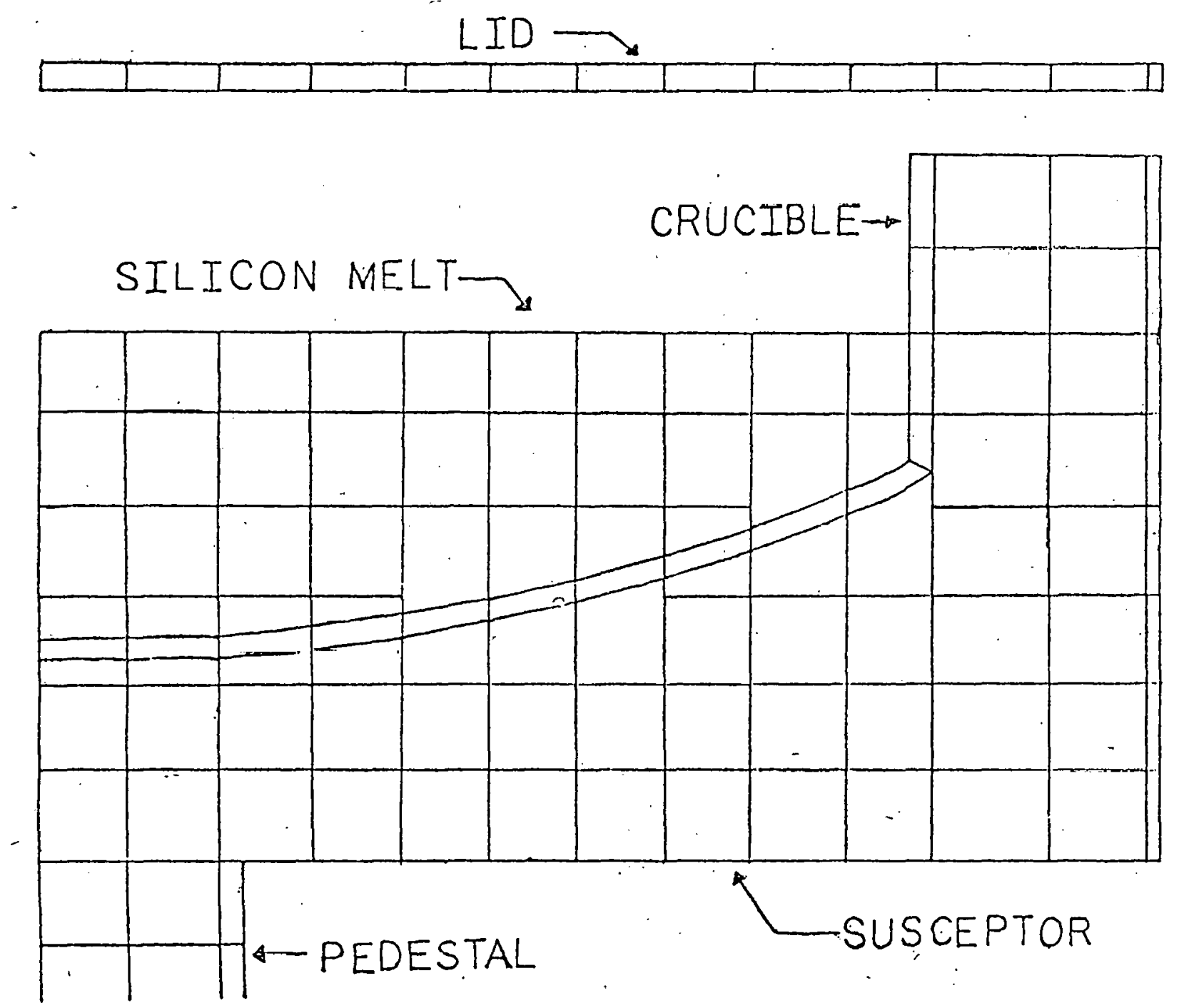

Figure 5. Thermal Model Modal Geometry Melt Crucible, Susceptor, and Lid 


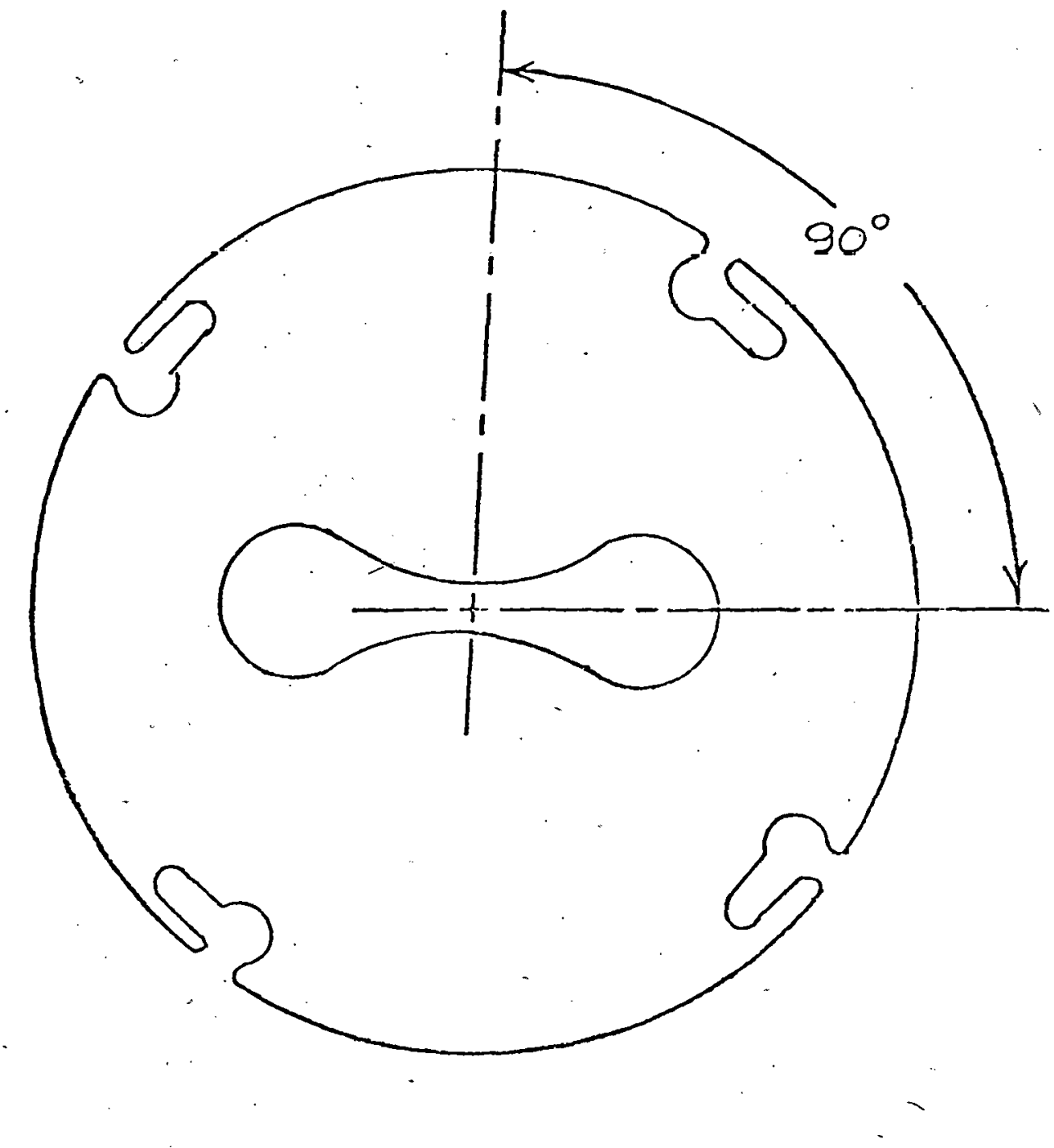

Figure 6 . Temperature Field of Each $90^{\circ}$ Sector is Identical Due to Symmetry. 
argon atmosphere also effects the lid temperature.

The LION-4 computer program is:being used to calculate the temperature field. The internal heat generation rate is specified and from that the temperatures are calculated.

A preliminary two dimensional model consisting of a single section has been completed and numerical results have been obtained. Only radiation heat transfer was assumed for the lid. As a result, the temperatures are considerably lower than experimental results obtained in the furnace. The model is currently being revised to include conduction and convection in the argon. It appears that the two-dimensional model will be extremely useful in investigating the thermal characteristics of the system.

Although the azimuthal temperature variations are not determined by the model, many other characteristics can be studied with it. Computer run time is significantly less for the two-dimensional model, therefore, it is hoped that much of the thermal analysis will be performed with this. model rather than the three-dimensional model which presently remains to be completed. 


\section{T.E. 2.2: Structural Characterization}

This period was spent in gathering data on:

(a) dimensions of dendritic web growth;

(b) twin spacing in grown dendritic web;

(c) number of twins in primitive dendrites;

(d) twin spacing in primitive dendrites.

Representative date of the above is given in the section of this report on Summary of Characterization Data.

T.E. 2.3: Electrical characterization; web bulk silicon

Data was collected during this report period on the resistivity and charge carrier type of the dendritic web samples grown. In all cases the samples were p-type ranging in resistivity from 2 to over $100 \mathrm{ohm}-\mathrm{cms}$.

Representative data of the above is given uncier the section on Sumnary of Characterization Data.

Wurk also has been carried out to develop a technique for applying test patterns on narrow web (less than $5 \mathrm{~mm}$ ) in order to electrically characterize these materials. Conventional techniques used for wafers have been found inappropriate due to geometric difficulties with the small size samples. Two techniques for applying appropriate metallization patterns on the web are being pursued. The first involves the development of a system for projecting the test pattern images directly onto the web surface without direct contact of the test pattern mask onto the surface of the web. The second involves the development of a flexible acetate mask that can be applied directly to the web surface by means of an adhesive layer. Neither of these techniques has been developed to the extent that they can be tested as yet. 
T.E. 2.4: Electrical characterization; web solar cells

With the exception of setting up a standard solar cell facility, work in this area was held in abeyance pending the completion of the program to grow seed dendrites for the determination of the optimum twin spacing for web growth. 
Interpretation of Results and Application to Program Goals

The primitive dendrites containing the appropriate range of twin spacing, 0.1 to $9 \mu \mathrm{m}$, have been grown. Seed dendrites for web growth have been produced from the majority of these primitives. Upon completion of the growth of the seed dendrites, this will complete the second phase of our growth program - the first phase consisting of setting up and putting in operation the growth facility having been completed in the first quarter of the contrart, Having obtained the appropriate seed crystals, efforts will now be centered on investigating their suitability for growing web; and once having determined the optimum twin spacing for web growth, work will then be devoted to the determination of the maximum width and pull rate that can be obtained for the growth of web crystal from the dendritic seeds with the optimum twin spacing.

The computer programs for the analys is of web growth have been developed to the stage that feedback between the analytical results and experimental configurations is now possible, enabling a more systematic and quantitative approach to optimizing the thermal conditions for web growth.

Preliminary characterization data taken indicate that these facilities will be adequate in determining the quality of the web produced in our growth facility.

Tentative Conclusions and Recommendations

The experimental facilities and thermal analysis computer programs have been developed and are adequate for meeting the goals of this program. It is recommended that the program proceed as planned as it is felt that 
the goals of the program will be met with this plan as scheduled.

Engineering Drawings and Sketches

The drawings and sketches generated during this report period are incorporated in the text of this report as figures 1 through 6 .

Projection of Activities for Succeeding Three Montins

The projected activities for the next three months are as listed

below:

(a) Completion of growth of seed dendrites from primitive dendrites;

(b) Initiation of studies to deternine optimuin twin spacing in seed dendrites for web growth;

(c) Refinement and continued development of computer programs for the web-growth analysis;

(d) Thermal probing of the silicon melt and incorporation of the data into the thermal anaiysis of the web groivth.

Summary of Characterization Data

Table I gives the number of twin planes and twin plane spacings for representative prinitive dendrites grown during this report period.

Table II gives representative values of resistivity and resistivity type found for web samples grown during this report period. 
TABLE I

Table of Twin Spacings from Primitive Dendrite Pulls

No. of Twin Planes

5

4

3

2

.
Twin. Plane Spacings ( $\mu \mathrm{m})$

\begin{tabular}{rrrr}
1 & 2 & 3 & 4 \\
\hline 0.4 & 0.4 & 0.1 & 1.9 \\
1.6 & 2.4 & 1.0 & \\
8.0 & 2.0 & 10.0 & \\
19.2 & 1.0 & 8.8 &
\end{tabular}

$2.0 \quad 1.0$

$4.0 \quad 7.0$

$4.4^{\prime} 2.0$

$8.0 \quad 2.0^{\circ}$

1.90 .8

$8.8 \quad 1.0$

$0.8 \cdot 0.6$

$8.5 \quad 0.3$

14.0

12.0

9.4

7.0 。

6.4 


\section{Table II}

Data on Resistivity

Sample

2-23-76-A-2

3-19-76-A-2

4-7-76-E-5

4-7-76-F-16

3-19-76-A-1

3-8-76-A-1

3-8-76-A-3

4-7-76-E-1

4-7-76-F-1

2-23-76-A-1

3-19-76-A-9

3-19-76-A-10

4-7-76-A-2

2-23-76-B-2

4-2-76-B-1

4-2-76-A-1

4-7-76-E-3.5
Type

$P$

P

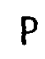

p

P

$\mathrm{P}$

$p$

$\mathrm{P}$

P

P

P

$\mathrm{P}$

$\mathrm{P}$

$p$

$p$

$\mathrm{P}$

$p$
Resistivity (ohm-cm)

2.33

3.55

5.10

6.86

7.65

8.13

10.03

11.48

12.70

13.86

15.70

16.50

18.40

19.70

20.90

22.18

34.34 


\section{PR.OGRAM PLAN}

WEB-DENDRITIC RIBBON GROWIH

UNIVERSITY OF SOUTH CAROLINA

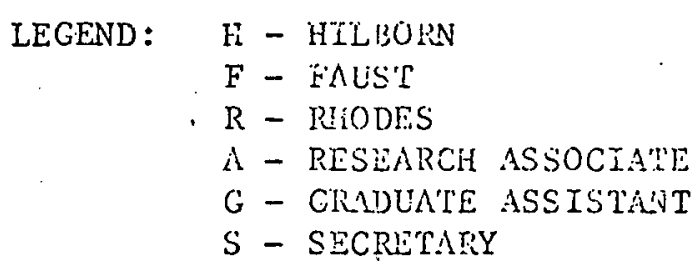

(Figures in columns represent man hours comitted)

CONTRACT NO. 954344

PERIOD: 1 OCTOBER 1975 - 1 MAY 1977

LPDATED 26 May 1976 
1. Web Growth, Growth Analysis

1.1 Set up wab furnace

1.1.I Level, align, calibrate gas flow, measure piysical/mechanical parameters

1.1.2 Iastrument melt temperature sensors, run furnace and RF generator

1.1.3 Calibrate $R F$ generator controls to melt temperature, no web pulling

1.2 Web growth, manual batch

1.2.1 Pull nominal web based on 1965 experience, establish measurements baseline. (Instrument melt level measurement), correlate with crystallization kinetics and seeding requirements

1.2.2 Vary pull rate, measure effects, correlate with crystallization kinetics and seeding requirenents

1.2.3 Vary $R F$ heat transfer rate, measure effects, correlate with crystellization kinetics and seeding requirements

1.2.4 Couple RF heat transfer rate and pull rate variations, measure effects, correlate with crystallization kinetics and seeding requirements

1.2.5 Final experimental design $-$

1.2.6 Final manual variation of manipulated variables, correlation with crystalliza tion kinetics and seeding requirements

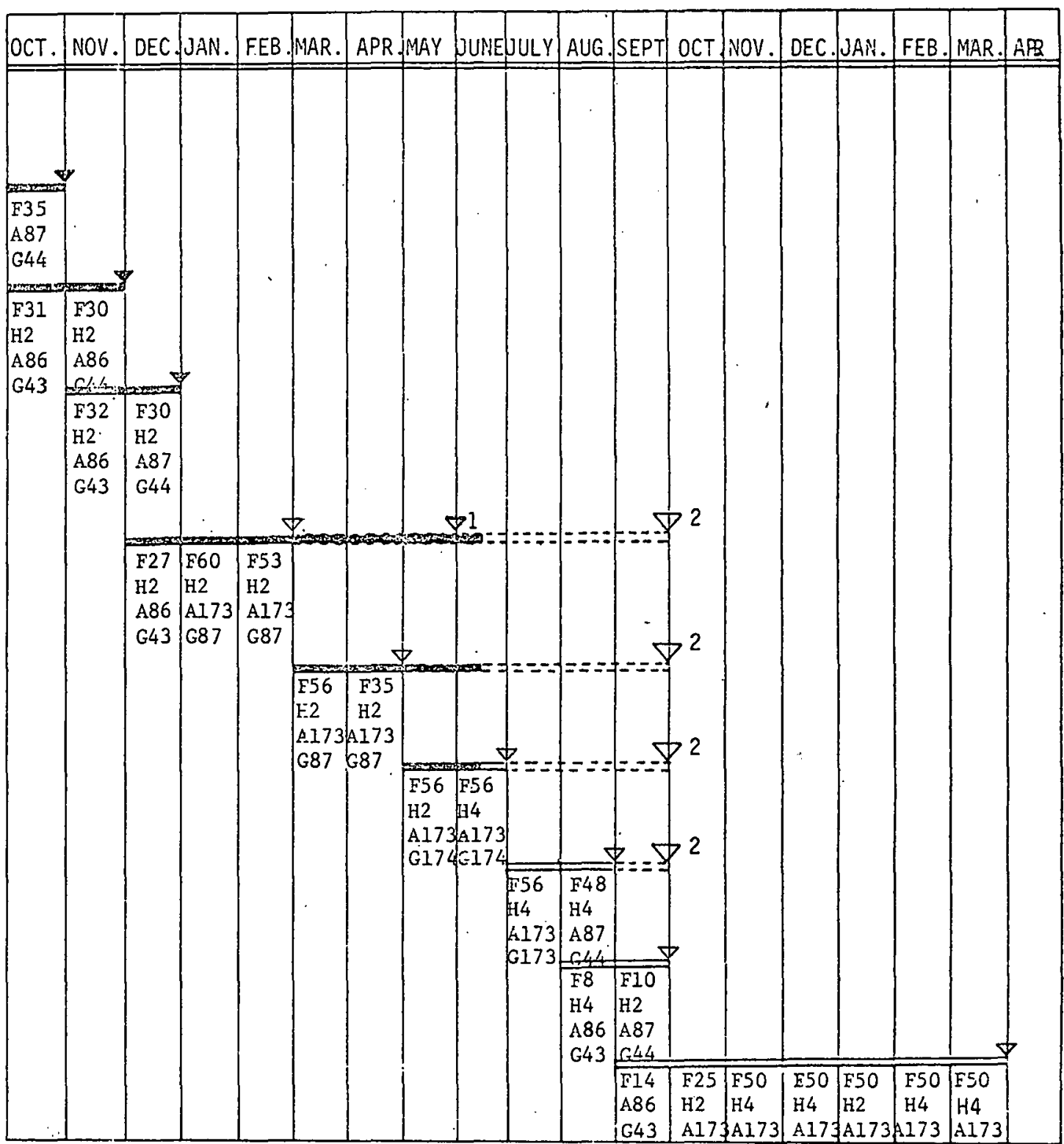


1.3 Web growth analysis

1.3.1 Develop semi-empirical multivariate static model-from web growih mar:ual experiments

1.3.2 Thermal web growth analysis

1.3.3 Correlate analysis, experimental data, and semi-empirical model

2. Weij Characterization

2.1 Development of sampling strategy, prototype tẹchnique

\subsection{Structural characterization}

2.3 Electrical characterization, web bulk silicon

2.4 Electrical characterization, web solar cells

3. Documentation, Program Review

3.1 Documentation

3.1.1 Initial financial managenent report. and program plan

3.1.2 NASA Form 533M MAR 73, JPL 3645, JPL $3545-1$

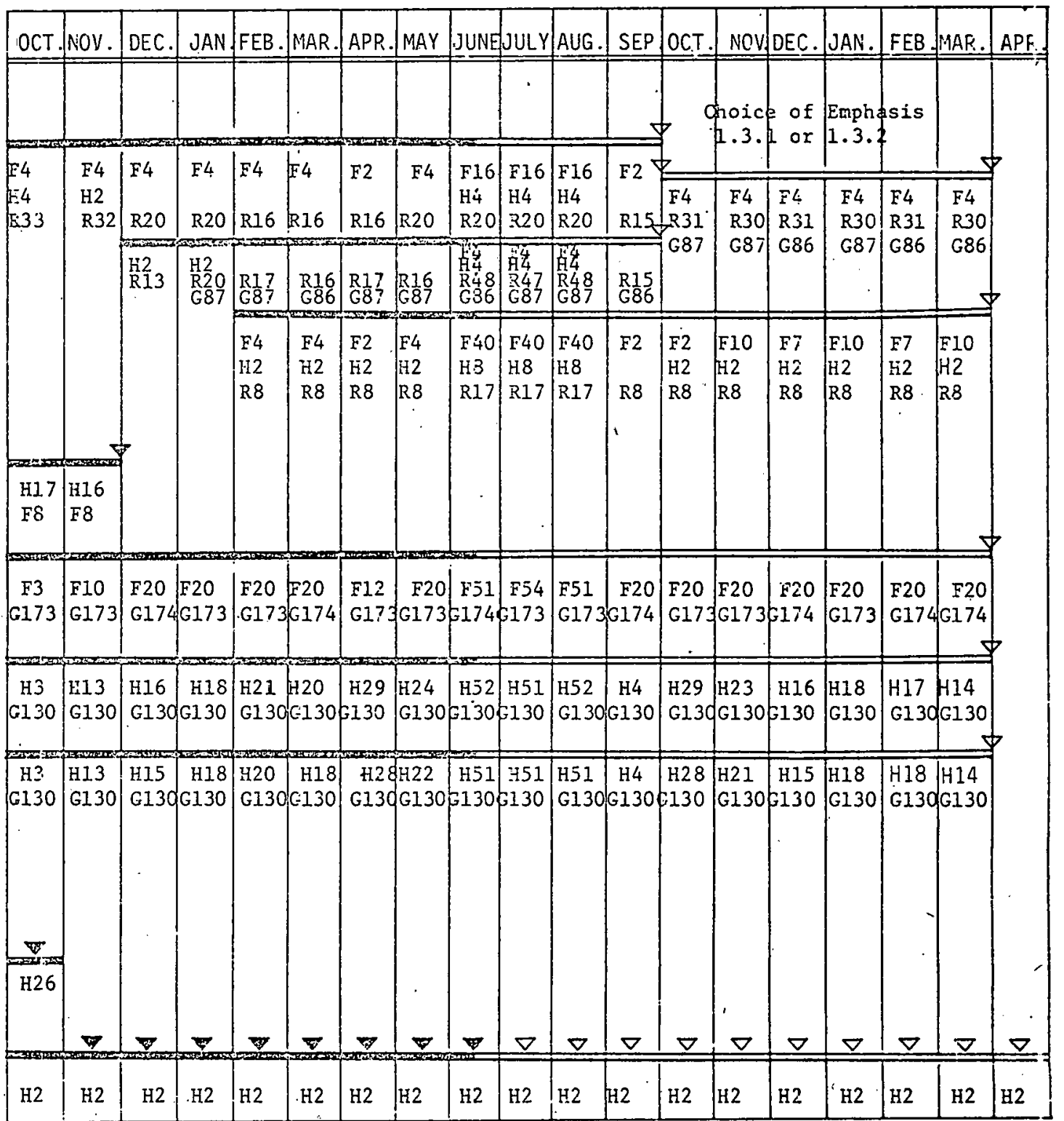


3.1.3 Monthly technical progress report ,.

3.1.4 Quarterly report

3.1.5 Interim summary

3.1 .6 Annual report

3.1.7 Draft final report

กั

3.1.8 Approved final report

3.2 Program review, work sessions 3.2.1. USC in-house review

3.2.2 JPL frogram review

3.2.3 Task integration sessions

3.2.4 Annual workstop

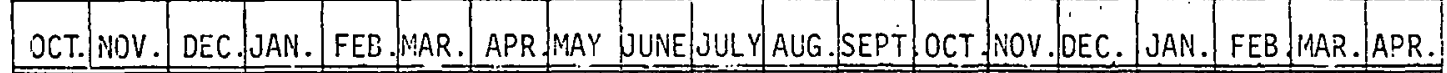

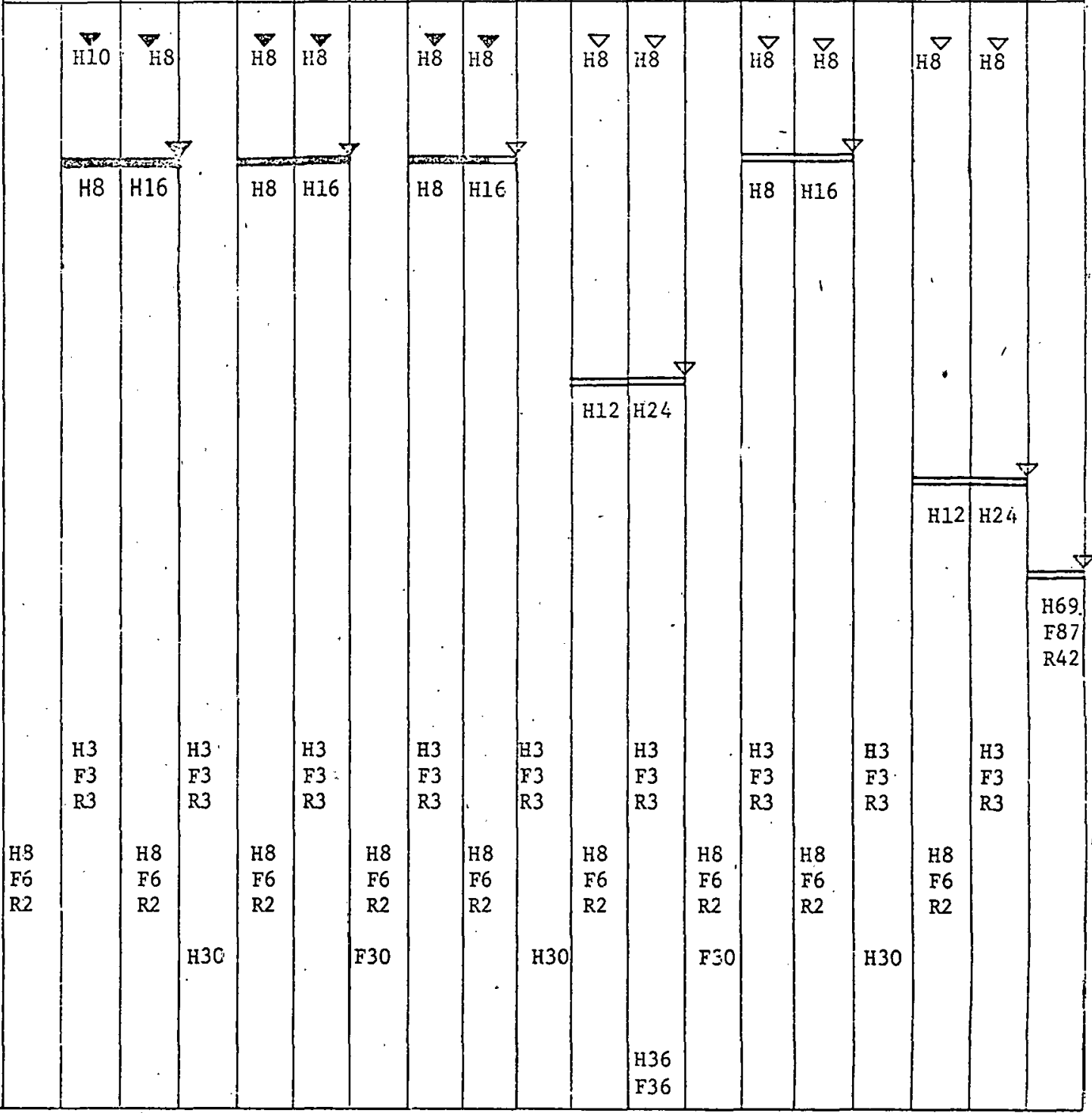


3.2.5 Design and performance review

\section{General Administration}

5. Planned Cost. (Thousands of dollars) Incurred Cost (Thousands of dollars)

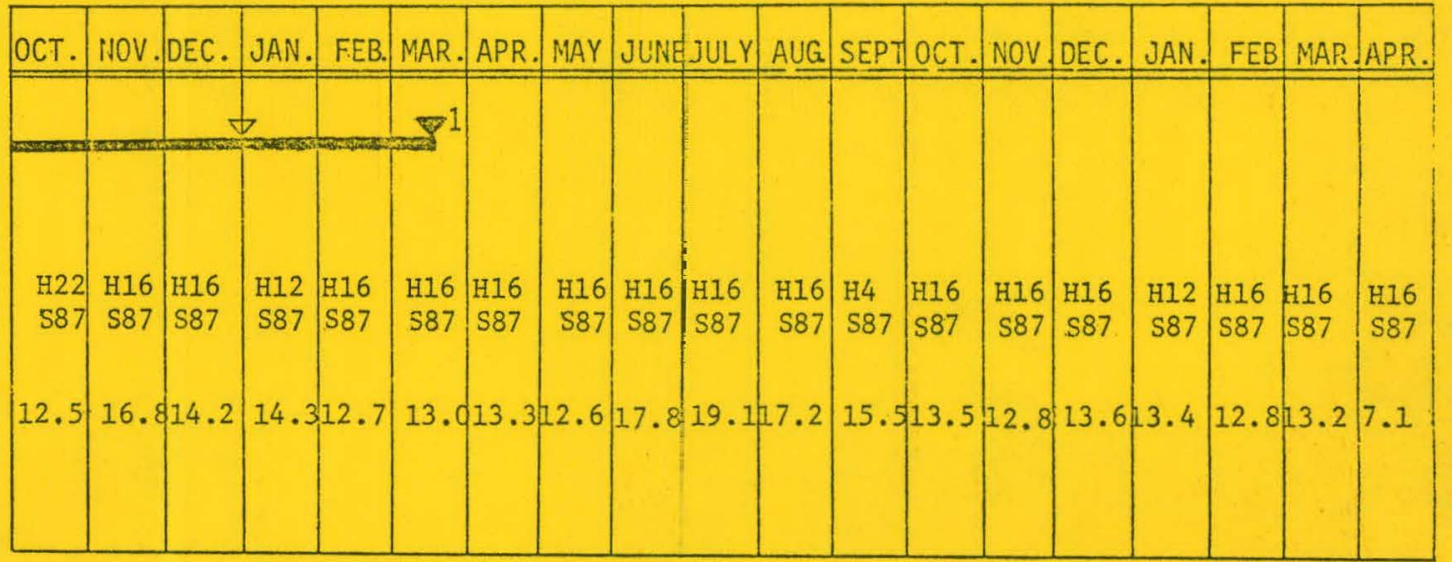

